\title{
Oil prices and stock returns: nonlinear links across sectors
}

\author{
Carlos Pinho ${ }^{1}$ \& Mara Madaleno ${ }^{1}$
}

Received: 29 September 2013 / Accepted: 18 April 2016/Published online: 28 April 2016 \# ISEG 2016

\begin{abstract}
We present evidence of an asymmetric relationship between oil prices and stock returns. The two regime multivariate Markov switching vector autoregressive (MSVAR) model allow us to capture the state shifts in the relationship between regional stock markets and sectors. Results suggest that oil price risk is significantly priced in the sample used. The impact is asymmetric with respect to market phases, and regimes have been associated with world economic, social and political events. Our study also suggests asymmetric responses of sector stock returns to oil price changes and different transmission impacts depending on the sector analyzed. There is a high causality from oil to sectors like Industrials and Oil \& Gas. Companies inside the Utilities sector were more able to hedge against oil price increases between 2007 and 2012. Historical crisis events between 1992-1998 and 2003-2007 do not seem to have affected the relationship between oil and sector stock returns, given the higher probability of remaining smoother. For all sectors there seems to be a turn back to stability from 2012 onwards. Finally, investors gain more through portfolio diversification benefits built across, rather than within sectors.
\end{abstract}

Keywords Oil prices $\cdot$ Nonlinear adjustment $\cdot$ Sector stock markets $\cdot$ Markov-switching models

JEL classification $\mathrm{C} 22 \cdot \mathrm{E} 32 \cdot \mathrm{F} 30 \cdot \mathrm{G} 12 \cdot \mathrm{G} 15 \cdot \mathrm{Q} 43$

Mara Madaleno
maramadaleno@ua.pt

1 GOVCOPP - Unidade de Investigação em Governança, Competitividade e Políticas Públicas DEGEIT - Departamento de Economia, Gestão, Engenharia Industrial e Turismo, Universidade de Aveiro, Campus Universitário de Santiago, 3810-193 Aveiro, Portugal 